\title{
CONTRIBUTING TO THE SOCIOCULTURAL ADAPTATION OF MIGRANTS THROUGH POSITIVE INTERACTIONS AT RUSSIAN LANGUAGE CLASSES
}

\author{
Anna Borissova ${ }^{1 *}$, Ekaterina Kozlovskaya ${ }^{2}$ Ekaterina Kulikova $^{3}$ \\ ${ }^{1}$ Dr. Anna Borissova, RUDN University, RUSSIA, borissovaa_anna@mail.ru \\ ${ }^{2}$ Dr. Ekaterina Kozlovskaya, RUDN University, RUSSIA, elaguaverde@yandex.ru \\ ${ }^{3}$ Dr. Ekaterina Kulikova, RUDN University, Kulikova-ekyu@rudn.ru \\ ${ }^{*}$ Corresponding Author
}

\begin{abstract}
This article highlights the role of sociocultural competence in teaching Russian as a foreign language (RFL) for labor migrants. In recent years, the modern education system has undergone fast expansion, which is caused by both external and internal reasons: new students' needs and interests, changing requirements of the society for learning activities results, social procurement and etc. One of the most basic reason that has made significant changes to the traditional academic model of teaching Russian as a foreign language is a social procurement program for labor migrants who come to work from the CIS countries. In order to work in Russia and interact with Russians, a labor migrant needs to integrate himself into the Russian communicative (linguistic and cultural) space. Integration of a foreign citizen in Russia is impossible without knowledge of the Russian language. Taking into consideration a well-known fact that language and culture are tightly connected, nobody can communicate without expressing his/her culture. Therefore, sociocultural competence is an ability to communicate in a language appropriately, situationally and culturally. It is the knowledge of history, traditions, customs, rules, beliefs and principles of a host society. Current research shows that in the past ten years, the majority of labor migrants arriving in Russia have a low ability to speak Russian or do not speak it at all. The situation is also compounded by lack of cultural awareness. In this regard there is a particular need for special training and updating of educational practices in order to facilitate a fair and effective migrant integration in Russian society. The aim of the article is to find out to what extent sociocultural aspect is incorporated in modern RFL teaching system for labor migrants, as well as to suggest possible ways to improve this insufficiency.
\end{abstract}

Keywords: Russian as foreign language, sociocultural competence, labor migrants, educational practices.

\section{INTRODUCTION}

Like any other large country, Russia is an important destination for migration, attracting a large number of labor migrants, both temporary and those who expect to connect their lives with Russia, as well as former compatriots applying for citizenship. According to statistics, at the beginning of 2020, the total number of migrants in the Russian Federation was 11.9 million. Naturally, it is worth considering that relatively recently Russia was in a different state formation, therefore the main directions of migration are the former union republics: Ukraine, Kazakhstan, Uzbekistan, Belarus, Azerbaijan, Georgia, Armenia, Tajikistan. The most attractive cities for labor migrants are such large Russian megalopolises as Moscow, St. Petersburg, Novosibirsk, Krasnoyarsk, Yekaterinburg. More detailed statistical data reflecting the migration pattern on the 
territory of the Russian Federation can be presented in the following table.

Fig. 1: The number of arrived labor migrants in the Russian Federation in 2020

\begin{tabular}{|c|c|}
\hline State & $\begin{array}{c}\text { Number of migrants, } \\
\text { mln }\end{array}$ \\
\hline Ukraine & 3,3 \\
\hline Kazakhstan & 2,5 \\
\hline Uzbekistan & 1,1 \\
\hline Azerbaijan & 0,77 \\
\hline Belarus & 0,76 \\
\hline Georgia, Armenia, Tajikistan & 3,47 \\
\hline
\end{tabular}

Currently, one third of all migration flows in Russia is arriving in Moscow, and the number of migrants is constantly growing. In the future, this trend will only strengthen as the demand for migrants is driven by economic reasons. Migrants have become and will remain a structure-forming factor in the economy of a large city, which cannot function successfully without their involvement. In this regard, it is obvious that the search for answers to the questions is becoming extremely urgent: how successfully are migrants entering a new environment for them and what is the level of adaptation among those people who come to the capital and stay here to live, work, give birth and raise children?

To work in Russia and interact with Russians, a labor migrant needs to integrate into the Russian cultural and linguistic space. From a psychological point of view, in order to enter a new social environment and a new community, a migrant needs to have high social and communicative competence. These qualities, in turn, are determined by a low level of aggressiveness and the ability to cooperate. These are socially acceptable and socially demanded qualities. That is, not only the migrant him/herself, possessing these qualities, will successfully function and develop in a new place, but also their presence among migrants allows the megalopolis to develop successfully and crisis-free (Bondareva, Kolesov, 2004).

It is obvious that successful adaptation of a migrant in society directly depends on his/her knowledge of the language of the host country. However, the communicative space in which a migrant finds him/herself consists not only of the linguistic component. The cultural component of the host country's communicative space plays no less important role in the adaptation of the migrant than the linguistic one. The introduction of a cultural component in the classes for studying the language of the host country contributes to an easier and faster adaptation of the migrant to a new society for him/her. One of the cultural practices in the classes for language studying is online excursions around the city, in which the migrant adapts and subsequently must integrate into society. Since a migrant, as a rule, has many other tasks that he/she must urgently solve (housing, work, obtaining the necessary documents), it is difficult for him/her to choose the time for a cultural walk, both on his/her own or accompanied by a guide or a teacher. In this situation, online city tours are preferable to walking tours: online tours are conducted directly in language classes, that allows the migrant to get acquainted with the urban environment and the culture of the host country in the process of learning the language.

\section{RESEARCH PROBLEM STATEMENT}

In recent years, the quota of labor migrants arriving in Russia has changed significantly - many either do not speak at all or do not speak Russian well. In this regard, the issue of the need for training of visiting labor migrants becomes relevant, the problem of improving the educational process aimed at the effective integration of labor migrants into the communicative space of Russian regions is no less important. Thus, the training of labor migrants is becoming a global problem, primarily for the methodology of teaching Russian as a foreign language. This problem is actively developing in the works of Russian teachers, psychologists, philologists, methodologists (Balykhina, 2007; Chelyshkova, 2002; Rumyantseva, 2007 and others). Nevertheless, despite active searches, the state of this problem has a number of contradictions regarding the methodological potential of the leading Russian scientific schools (Moscow State University, RUDN 
University, the Pushkin State Art Institute, St. Petersburg State University):

- Between the state directive in the field of migration processes, the introduction of a compulsory examination and actual absence (linguistic and cultural) programs, state institutions that ensure the adaptation of labor migrants;

- Between the need for tolerant communication in the Russian society and the absence of an ethnocultural component in teaching Russian language to labor migrants that can have a significant impact on the formation of a student's socio-cultural competence;

- Between the rich experience of Russian science, practice of teaching Russian as a foreign language and the poorly developed practice-oriented programs and courses in the field of training modern labor migrants from the CIS countries in the Russian language, it prevents them from entering the communicative space of Russia;

- Between the content component of the communicative development of labor migrants and lack of clear differentiation in accordance with the goals (for work, for obtaining a temporary residence permit, obtaining a residence permit, obtaining Russian citizenship), communicative needs (a set of communicative situations corresponding to the peculiarities of the representatives national outlook of this or that ethnic groups);

The above contradictions have led to the formulation of the research problem, namely: the need to look for various approaches, forms and methods for the formation of socio-cultural competence of migrants, based on modern approaches, principles and technologies, to test and actively introduce them into the learning process in the teaching methodology of RFL.

\section{METHODOLOGY}

When constructing an effective socio-cultural model of teaching Russian as a foreign language (RFL) to labor migrants from the former CIS countries, it is necessary to think in detail about linguo-methodological methods. Within the framework of this article, we believe that teaching RFL should necessarily be based on the principles of the axiological approach, which has been repeatedly highlighted in studies of Russian (Balykhina, 2000; Deikina, 2019; Prokhorov, 2016; Erokhina, 2017) and foreign specialists (Burchett, 2000; Carr, 1998; Kaliannan, Chandran, 2010). The essence of this approach lies in the fact that in the process of experiential learning, not only universal human values are considered, but also the socio-cultural values of both Russians and the migrants themselves. As a result of comparing common ethnic values the student begins to navigate in the world of cultural values of another people faster. The analysis of sociocultural values of the people whose language the labor migrant is studying makes it possible to make the learning process value-oriented. A migrant being trained, based on national values known and understandable by him/her, learns "new" values, increasing his/her own axiological potential. As a result, a "natural" adaptation of the migrant takes place through the assimilation of patterns fixed in the Russian language, and Russian communicative space becomes understandable, the line between "us" and "them" is erased. Teaching labor migrants on the basis of an axiological approach allows to motivate him/her not only to solve communication problems (everyday level, in the sphere of professional activities, etc.) in a new communicative space, but also to further study the language as a part of culture. This approach logically explains the principle that teaching the Russian language to labor migrants, when combined with the study of the culture of the Russian people, implies not only understanding the linguistic picture of the world of another nation, but also understanding the native culture and native language, and thereby connects the model of teaching the Russian language to labor migrants with culturological approach, which determines the content of the didactic material, the choice of methods for introducing this material into the learning process, etc. Analyzing the practical experience of working with migrants, we have come to the conclusion that in the learning process it is very important to focus on culturally marked phenomena that contain information about Russian culture, life, traditions, spiritual and material values of the Russian people as a national and cultural community, etc. This approach allows the formation of a secondary linguistic personality (the term was introduced by Irina I. Khaleeva). Due to the fact that the formation of a secondary linguistic personality is "getting accustomed to" the culture of another people, it is necessary to use the entire arsenal of traditional and modern methods and technologies. The formation of the thesaurus of the secondary linguistic personality, in particular, the explanation of the cultural component of words and phrases in the texts and discourse (for example, such as: family, man, woman, etc.), will make the process of learning the Russian language for labor migrants more attractive and meaningful. Of course, regarding labor migrants who come only to carry out labor activities (category "foreign worker"), we can only talk about the "starting" stage of the formation of a secondary linguistic personality, but "getting accustomed to" culture leaves an imprint on the student's worldview, allows him/her, if not to accept another culture, another language, then begin treating 
them with understanding, thanks to understanding of culturally marked linguistic units. The socio-cultural approach to teaching RFL also teaches migrant students to be tolerant. Tolerant approach is manifested in the formation of a respectful, sensitive attitude to another culture, another linguistic personality, in modeling "basic concepts of Russian culture", in comparing Russian concepts with the basic concepts of the culture native to migrants, isolating a common semantic, conceptual core of meanings of mentally different peoples. We believe that already in the implementation of linguistic training of labor migrants belonging to the category of "foreign worker", special attention should be paid to situations, behavioral stereotypes and language design in these communicative acts, and, thus, to form an understanding of habits, "oddities" in speech behavior of representatives of other nationalities, as well as pay attention to the "similarity" of communicative situations, understandable to both Russians and representatives of other nationalities, and only then introduce speech situations that are incomprehensible to the labor migrant. It is the "unifying", not the "dividing" one that will allow the migrant to productively resolve the contradictions of the unfamiliar sociocultural environment.

\section{DISCUSSION}

\subsection{Online Excursions in Russian Language Classes as an Effective Way of Social and Cultural Adaptation of Migrants}

In this article, the study was conducted, its purpose was to test the effectiveness of online excursions as a cultural component in the classroom in Russian as a foreign language. The hypothesis of the study is that the use of online excursions improves the quality of the sociocultural training of migrants and facilitates their adaptation to the communicative space of the host country.

The study was based on preparation courses for passing a comprehensive exam for labor migrants operating at the Faculty of Advanced Training for Teachers of Russian as a Foreign Language at RUDN University. The study was conducted from September to November 2019. It was attended by 23 testers labor migrants from Uzbekistan, Tajikistan, Kyrgyzstan, Ukraine and Moldova.

The obligatory three-component comprehensive examination for labor migrants was introduced in Russia in 2015. Foreigners attending courses to prepare for the comprehensive exam at the Faculty of Advanced Training for Teachers of Russian as a Foreign Language at RUDN University have significant difficulties in adapting to life in Russian society, which is due to a number of factors. The first factor is associated with poor knowledge or complete lack of proficiency in the Russian language of migrants coming to the courses. This factor significantly hinders the process of adaptation of a migrant in the country and prevents him/her from leading an active social life. The second factor is that migrants do not know the main events of Russian history and some of the historically formed features of Russian culture. This factor is responsible for the fact that newcomers do not understand a number of Russian cultural codes, which in turn provokes problems in communication with Russians, even considering the migrant's command of the Russian language. The third factor is associated with the lack of knowledge among migrants about the peculiarities of the functioning of Russian state institutions. This factor leads to a vague idea among migrants about their rights on the territory of the Russian Federation, also to misunderstanding of how to solve the arising legal difficulties and where to turn for help in legal matters.

One of the priority tasks of the courses for preparing for the comprehensive exam for labor migrants operating at the Faculty of Advanced Training of Teachers of Russian as a Foreign Language at RUDN University is to solve the above difficulties for foreigners attending classes. Conducting online excursions in Russian language classes was aimed at working with the first two factors: in the process of learning the Russian language, migrants got acquainted with the peculiarities of Russian culture, which was supposed to facilitate and speed up the process of their adaptation. To conduct online excursions, course teachers could choose any resource that they considered the most convenient for work. Considering the extremely low level of Russian language proficiency of the migrants attending the courses, teachers refused to use Internet resources that provide access to video excursions voiced by professional guides or announcers. For effective lessons, it seemed inappropriate to turn to material created at a much higher level of language proficiency than the students had. For this reason, teachers preferred to build online excursions using resources that provide photos or $3 \mathrm{D}$ images of Moscow streets. The use of such resources contributed to building a variable route of the excursion, which could be adapted to the interests of a specific group of students. The teachers chose the following websites for online excursions as the most convenient in class with migrants:

- Online excursions in the Kremlin: https://www.sputnik8.com 
- Yandex. Panoramas: https://yandex.com/support/maps/concept/panoramas.html

The Yandex. Panoramas is not a specialized site for online excursions. However, it was this portal that the teachers marked as the most convenient, since its use provided an online excursion around the area of Moscow that aroused the strongest interest of the group. For information content the teachers used materials from various sources, including the websites of different Moscow museums and adapted them to an elementary or basic level of Russian language proficiency, depending on the knowledge of the audience. Before the online excursion, the teachers conducted a series of exercises to make it easier for the students to comprehend the information on the excursion. These exercises were based on various types of speech activity. Among them were exercises for reading and understanding microtexts, listening of information, as well as an exercise for retelling read or heard information. When conducting online excursions, teachers told students about the history of Moscow streets, about what this or that building is known for. During the online excursion, the teachers also modeled the communicative situations that migrants may face in the urban environment. The communicative task was as practical as possible - to help migrants move freely around the city, considering the knowledge of the Russian language at an elementary level. As a result, the main questions were the following: "Where is ...?", "How to get to ...?", "How can I get to ...?" and a number of others. The implementation of communicative situations was carried out in the form of dialogues, first between the teacher and the students, and then between the students themselves.

\section{RESULTS}

The verification of the data obtained in the course of the study was carried out on the effectiveness of the use of online excursions during Russian language classes in accordance with two criteria: objective and subjective. The objective criterion was the result of a comprehensive examination in the Russian language, history and fundamentals of the legislation of the Russian Federation, which was taken by migrants at the end of the course. In a group of 23 trainees who attended the courses, everyone passed the comprehensive exam without difficulty.

The second criterion for assessing the results of the study was subjective - this is the personal opinion of a migrant student about the practice of online excursions in Russian language classes. To implement this criterion, during the last class in the Russian language, an anonymous survey (questionnaire) was conducted among students at the migrant courses, in which migrants assessed the practical benefits of online excursions. Students were asked to rate online excursions on the following points: ease of adaptation in an urban environment (from 0 to 5 , where 1 is the lack of facilitation of the adaptation process, and 5 is its maximum facilitation); acquaintance with the peculiarities of Russian culture (from 0 to 5 , where 1 - the student believes that he/she did not get acquainted with the peculiarities of Russian culture, and 5 acquaintance with the peculiarities of Russian culture took place); ease of assimilation of the information offered during the excursion in Russian (from 0 to 5 , where 0 - it was extremely difficult to understand the information, and 5 , on the contrary, - the perception of information did not cause any difficulties); The results of the survey are presented in Figure 2.

Fig.2: Online excursions rating

\begin{tabular}{|l|l|l|l|}
\hline Criterion & $\begin{array}{l}\mathbf{5} \text { points } \\
\text { (number of } \\
\text { people) }\end{array}$ & $\begin{array}{l}\mathbf{4} \text { point } \\
\text { (number of } \\
\text { people) }\end{array}$ & $\begin{array}{l}\text { 3 points } \\
\text { (number of } \\
\text { people) }\end{array}$ \\
\hline $\begin{array}{l}\text { Ease of adaptation } \\
\text { in an urban } \\
\text { environment }\end{array}$ & 19 & 4 & 0 \\
\hline $\begin{array}{l}\text { Acquaintance with } \\
\text { the peculiarities of } \\
\text { Russian culture }\end{array}$ & 16 & 4 & 1 \\
\hline $\begin{array}{l}\text { Ease of } \\
\text { assimilation of the } \\
\text { information offered } \\
\text { during the } \\
\text { excursion in } \\
\text { Russian }\end{array}$ & 18 & 5 & 0 \\
\hline
\end{tabular}


It can be seen from this table that none of the subjects stated about the subjectively low efficiency of the practice of online excursions. In contrast, the participants' answers ranged from 5 to 3 points, that is, they can be attributed to the top of the rating scale. Thus, the use of online excursions in Russian language classes was subjectively assessed by the participants in the experiment as sufficiently useful.

\section{CONCLUSIONS}

The modern educational system of the Russian Federation is subject to changes in connection with new social orders. One of these orders is related to the preparation of labor migrants for the state exam (module "Russian language"). A labor migrant needs to be integrated into the Russian space and the Russian language is one of the factors that can either facilitate or hinder the adaptation of a labor migrant to a new cultural and linguistic space. The process of linguacultural adaptation is associated with the peculiarities of the system of the native language of a labor migrant, with the fact that he/she is forced to come into contact with a foreign culture, with a different worldview, etc., therefore, the issue of organizing a full linguistic support is so important. This support should focus on the linguistic culture, language system, speech traditions of the labor migrant, that is, based on the national and cultural characteristics of the student. When preparing for state testing and linguocultural adaptation of labor migrants from the former CIS countries to the Russian society, a flexible, easy-to-use model of teaching the Russian language using mixed forms of education (traditional, distance, Internet technologies, etc.) is needed, that will allow those who wish to master or improve communication skills in Russian. In addition, the use of information technologies in the formation of socio-cultural competence will bring the learning process closer to real conditions, create a convenient mode for learning, systematize work and allow the labor migrant to independently control the material learned.

The data obtained as a result of the study confirm the legitimacy of the hypothesis stated by the authors: the use of online excursions in Russian language classes for migrants is highly effective. Such excursions contribute to quick and comfortable linguocultural adaptation of migrants in society, since they significantly reduce the interlanguage barrier and introduce the cultural characteristics of the host country to social norms.

\section{ACKNOWLEDGEMENTS}

The article was written within the framework of the research topic "Functional distribution and typology of the need for languages among migrants in the urban environment" No. 056112-0-000.

\section{REFERENCE LIST}

Balykhina, T.M. (2007). Methods of teaching Russian as a Foreign Language (new): A textbook for teachers and students. Moscow.: RUDN University.

Balykhina, T.M. (2000). The structure and Content of Russian Philological Education. Methodological problems of teaching the Russian language. Moscow: MGUP Publishing House.

Burchett, B. L. (2000). The role of values in higher education: a case study of two higher education institutions. Diss. Degree Ed.D., East Tennessee State University.

Bondareva, S.K., Kolesov, D.V. (2004). Migration. Essence and Phenomenon. Moscow-Voronezh.

Carr, D. (1998). Common and personal values in moral education. Studies in Philosophy and education, 17 (4).

Chelyshkova, M.B. (2001). Theory and Practice of Constructing Pedagogical Texts. Moscow.

Deykina, A.D. (2019). Axiological Methods of Teaching the Russian Language. Moscow: Moscow State Pedagogical University.

Erokhina, E. L. (2017). New Competences in the Structure of Linguistic Personality of the Modern TeacherVerbal as a Reference Point of Modernization of Philological Education. Linguoratorial Paradigm: 
theoretical and applied aspects, 22 (1).

Kaliannan, M. \& Devi Chandran, S. (2010). Education in human values (EHV): Alternative Approach for a Holistic Teaching. Educational Research and Review, 5 (12).

Khaleeva, I. I. (1989). Fundamentals of the theory of teaching foreign speech understanding. Moscow: Vysshaya shkola.

Prokhorov, Yu. A. (2016). Russian Language in Intercultural Environment. Available at: http://tvkultura.ru/ (Retrieved on 03.11.2016).

Rumyantseva, N.M. (2007). Expansion of channels of perception as a technology for teaching foreign languages. Vestnik TsMO MGU. "Philology. Culturology. Methodology ", 7 (1-2). 